\title{
Measuring Antioxidant Activity in Bioorganic Samples by the Differential Oxygen Uptake Apparatus: Recent Advances
}

\author{
Riccardo Amorati, Andrea Baschieri, and Luca Valgimigli \\ Department of Chemistry “G. Ciamician”, University of Bologna, Via S. Giacomo 11, 40126 Bologna, Italy \\ Correspondence should be addressed to Riccardo Amorati; riccardo.amorati@unibo.it
}

Received 2 January 2017; Accepted 27 February 2017; Published 19 March 2017

Academic Editor: Jacques Lalevee

Copyright ( 2017 Riccardo Amorati et al. This is an open access article distributed under the Creative Commons Attribution License, which permits unrestricted use, distribution, and reproduction in any medium, provided the original work is properly cited.

The measure of $\mathrm{O}_{2}$ consumption during the inhibited autoxidation of an easily oxidizable substrate is one of the most reliable and predictive methods to assess antioxidant activity, especially for structure-activity relationship studies, for food and industrial applications. The differential oxygen uptake apparatus described herein represents a powerful and cost-effective way to obtain antioxidant activity from inhibited autoxidation studies. These experiments provide the rate constant and the stoichiometry of the reaction between antioxidants and peroxyl radicals $\left(\mathrm{ROO}^{\circ}\right)$, which are involved in the propagation of radical damage. We show the operation principles and the utility of this instrumentation in the bioorganic laboratory, with regard to the recent advances in this field, ranging from the study of natural antioxidants in biomimetic system, to the use of substrates generating hydroperoxyl radicals, and to the evaluation of novel nanoantioxidants.

\section{Introduction}

The reaction of organic substrates with atmospheric oxygen under mild conditions to form various oxygenated compounds such as hydroperoxides, peracids, epoxides, and ketones is called "autoxidation" [1]. It can either be beneficial, such as when it is used for the functionalization of organic compounds [2], or it can be detrimental as in case of food, oils, or polymers getting rancid or oxidized in the presence of atmospheric $\mathrm{O}_{2}$ [3]. Antioxidants are always present in natural and man-made oxidizable materials as a strategy to preserve them from the damage of autoxidation [4]. Moreover, the awareness of the importance of radical-mediated reactions in biology and the theories relating oxidative stress to aging and degenerative diseases represent another major factor promoting the study of antioxidants [5]. A correct and unbiased measure of the antioxidant activity is of fundamental importance for the evaluation of natural antioxidants and to guide for the design of new synthetic ones. To adapt to the different testing needs, an impressively large array of rapid assays has been proposed. These include methods based on inhibited autoxidation studies, which are performed by monitoring $\mathrm{O}_{2}$ consumption, or the formation of hydroperoxides (the primary oxidation products), or of secondary oxidation products like carbonyl compounds. When results are analyzed with a proper kinetic treatment, these methods are the most reliable to assess antioxidant activities [6]. Most testing methods, however, do not involve substrate autoxidation. They rely on the competitive bleaching of a probe (e.g., ORAC, luminol, and $\beta$-carotene bleaching assays) [7], or they are indirect methods based on the reduction either of persistent radicals (e.g., DPPH and TEAC assays) or of inorganic oxidizing species (e.g., FRAP and Follin-Ciocalteu assays) [8]. All such methods that are not based on the kinetic study of a substrate's autoxidation should be used with caution, only as preliminary indication, after careful consideration of the chemistry behind them, that is, bearing in mind what they are actually measuring. Failure to do so might result in unrealistic and scarcely meaningful data [6-9]. In this review, we describe how to measure the rate of inhibited autoxidation by using a differential oxygen uptake apparatus, and how to obtain accurate quantitative data of antioxidant activity from 


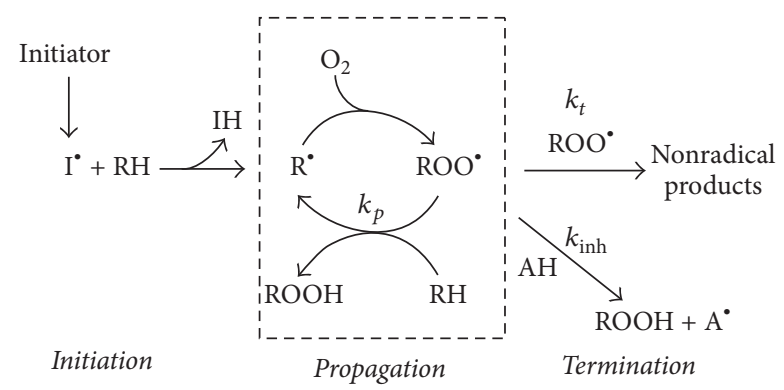

Scheme 1: Chain reaction of autoxidation for a substrate (RH) and mode of interference by chain-breaking antioxidants $(\mathrm{AH})$.

the analysis of $\mathrm{O}_{2}$-consumption traces. We show the utility of this instrumentation in the bioorganic laboratory with regard to the recent advances in this field, ranging from the study of natural antioxidants in biomimetic systems to the evaluation of novel nanoantioxidants.

\section{How to Determine the Antioxidant Activity from Inhibited Autoxidation}

Autoxidation follows a free-radical chain mechanism, depicted in its simplest form in Scheme 1.

Autoxidation can, in principle, be initiated by any reaction that generates free radicals. The most common initiating systems with practical relevance are the catalytic decomposition of hydroperoxides by transition metals ions (such as $\mathrm{Fe}^{2+}$ and $\mathrm{Cu}^{+}$) and the interaction of UV-vis light with photoinitiators (such as ketones and peroxides). However, because hydroperoxides (and peroxides) and ketones are also products of the autoxidation, their accumulation may lead to autocatalytic behavior consisting in an increasing rate of reaction with time [8]. When a controlled rate of initiation is desired, thermal decomposition of azo-initiator is preferred. The use of azo-initiators, such as the lipid-soluble AIBN $\left(2,2^{\prime}\right.$-azobis-isobutyronitrile), or water-soluble AAPH $\left(2,2^{\prime}\right.$ azobis(2-amidinopropane) dihydrochloride), is much more practical than metal catalysis or photoinitiation, because the homolytic decomposition of azo-initiators proceeds at constant rate at a given temperature, during the entire course of autoxidation, thereby providing a constant rate of initiation [10]. Following the mechanism reported in Scheme 1, the initiating radical $\left(\mathrm{I}^{*}\right)$ abstracts a $\mathrm{H}$-atom from the substrate, generating a carbon-centered (alkyl) radical, $\mathrm{R}^{*}$, which reacts with $\mathrm{O}_{2}$ to form a peroxyl radical $\left(\mathrm{ROO}^{\circ}\right)$. Except in some specific cases [11], this last reaction is very efficient [10]. For this reason, in the presence of atmospheric oxygen virtually all $\mathrm{R}^{\circ}$ are converted to $\mathrm{ROO}^{\circ}$, and peroxyl radical chemistry dominates autoxidation kinetics. The propagation can either consist of $\mathrm{H}$-atom transfer $\left(\mathrm{ROO}^{\circ}+\mathrm{RH} \rightarrow \mathrm{ROOH}+\mathrm{R}^{*}\right)$ or of addition to a $\mathrm{C}=\mathrm{C}$ double bond $\left(\mathrm{ROO}^{\circ}+\mathrm{X}=\mathrm{Y} \rightarrow\right.$ ROOX- $\mathrm{Y}^{*}$, where $\mathrm{X}$ and $\mathrm{Y}$ are substituted $\mathrm{C}$ atoms). Termination events consist mainly in the radical-radical self-quenching of peroxyl radicals to give nonradical products [1]. If propagation is fast enough, the overall process becomes a chain reaction and, after the initiation event, several propagation steps
TABLE 1: Rate constants for the autoxidation of selected organic substrates in $\mathrm{PhCl}$ at $303 \mathrm{~K}$.

\begin{tabular}{|c|c|c|c|}
\hline Substrate & $k_{p}\left[\mathrm{M}^{-1} \mathrm{~s}^{-1}\right]$ & $2 k_{t}\left[\mathrm{M}^{-1} \mathrm{~s}^{-1}\right]$ & $k_{p} /\left(2 k_{t}\right)^{1 / 2}$ \\
\hline Methyl oleate $^{\mathrm{a}}$ & 0.88 & $1.0 \times 10^{6}$ & $8.8 \times 10^{-4}$ \\
\hline Methyl linoleate $^{\mathrm{a}}$ & 62 & $8.8 \times 10^{6}$ & 0.021 \\
\hline Toluene $^{\mathrm{a}}$ & 0.24 & $3.0 \times 10^{8}$ & $1.4 \times 10^{-5}$ \\
\hline Styrene $^{\mathrm{a}}$ & 41 & $4.2 \times 10^{7}$ & $6.3 \times 10^{-3}$ \\
\hline Cumene $^{\mathrm{b}}$ & 0.32 & $4.6 \times 10^{4}$ & $1.5 \times 10^{-3}$ \\
\hline Tetrahydrofuran ${ }^{c, d}$ & 4.3 & $6.2 \times 10^{7}$ & $1.7 \times 10^{-4}$ \\
\hline 1,4 -Cyclohexadiene $e^{e}$ & 1400 & $1.3 \times 10^{9}$ & 0.038 \\
\hline Heptanal $^{\mathrm{f}, \mathrm{g}}$ & 2800 & $5.4 \times 10^{7}$ & 0.38 \\
\hline
\end{tabular}

can take place before the chain reaction is terminated. By solving the kinetic equations that describe the individual reactions depicted in Scheme 1 and applying the steady state approximation, oxygen consumption during the autoxidation of a generic substrate $\mathrm{RH}$ is described by (1), where $k_{p}$ and $2 k_{t}$ are, respectively, the propagation and termination rate constant for the autoxidation of the oxidizable substrate and $R_{i}$ is the initiation rate.

$$
-\frac{d\left[\mathrm{O}_{2}\right]}{d t}=\frac{k_{p}}{\sqrt{2 k_{t}}}[\mathrm{RH}] \sqrt{R_{i}}+R_{i}
$$

Since the autoxidation rate depends on the ratio $k_{p} /$ $\left(2 k_{t}\right)^{1 / 2}$, this quantity is commonly referred to as the oxidizability of the substrate. Some examples of typical oxidizable substrates are given in Table 1, together with their respective $k_{p}, 2 k_{t}$, and $k_{p} /\left(2 k_{t}\right)^{1 / 2}$ values. From the values reported in Table 1, it is evident that the oxidizability of organic molecules varies considerably, from very low values for saturated hydrocarbons to 1000 -fold higher values for polyunsaturated hydrocarbons or for aldehydes.

Once the rate constants $k_{p}$ and $2 k_{t}$ are known, along with $R_{i}$ values, the effect of the addition of any modifier to the autoxidation can be studied. Some compounds can accelerate autoxidation, for example, by providing better chain transfer than peroxyl radicals, as observed in the case of $\mathrm{N}$ hydroxyphthalimide (NHPI) class of compounds.

It was shown that, after the addition of NHPI to the autoxidation of isopropylbenzene (cumene), the $\mathrm{O}_{2}$ consumption is increased because PINO radicals react with $\mathrm{RH}$ faster than ROO'. NHPI and related molecules can be used as metal-free catalysts for the functionalization of hydrocarbons (Scheme 2) [17, 18]. Addition of easily oxidizable compounds may either decrease or increase the rate of $\mathrm{O}_{2}$ consumption by cooxidizing with the substrate. Some of these systems have been investigated by us in the case of garlic sulfides and estragole $[19,20]$.

However, arguably, the most important class of compounds that are used to modify the rate of autoxidation is antioxidants, which are used by man and nature to slow down the degradation of organic materials under $\mathrm{O}_{2}[1]$. Depending 


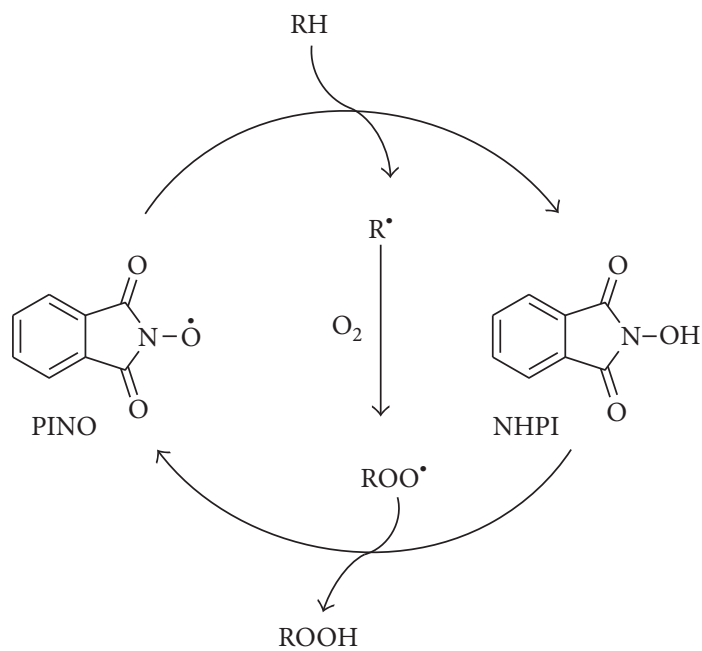

SCHEME 2: Acceleration of autoxidation of RH by NHPI/PINO catalysis.

on their mechanism of action, two main classes of antioxidants, preventive and chain-breaking, can be recognized. Preventive antioxidants reduce the probability of initiation: that is, they reduce the rate of initiation $R_{i}$ by eliminating the primary source of free radicals. For instance, they can reduce or decompose hydroperoxides into nonradical products, or they can chelate transition metal ions, removing them from the redox cycle (e.g., Fenton's reaction) that would cause the decomposition of peroxides into radical species [8]. On the other hand, chain-breaking antioxidants $(\mathrm{AH})$ react with peroxyl radicals to yield stabilized radicals $\left(\mathrm{A}^{\circ}\right)$ that are sufficiently unreactive toward the substrate $\mathrm{RH}$ to be unable to further propagate the oxidative chain. Rather, they are sufficiently long-lived to "wait" until they quench a second peroxyl radical ((2)-(3)) [8]. When this happens they are told to have a stoichiometric factor of 2 .

$$
\begin{aligned}
& \mathrm{AH}+\mathrm{ROO}^{\bullet} \stackrel{k_{\text {inh }}}{\longrightarrow} \mathrm{A}^{\bullet}+\mathrm{ROOH} \\
& \mathrm{A}^{\bullet}+\mathrm{ROO}^{\bullet} \longrightarrow \text { non-radical products }
\end{aligned}
$$

In the case of monophenols ( $\mathrm{ArOH})$, such as $\alpha$-tocopherol and 2,6-di-tert-butyl-4-methylphenol (BHT), the second $\mathrm{ROO}^{\circ}$ radical is trapped by addition on aromatic ring of $\mathrm{ArO}^{\circ}$, whereas in the case of catechols $\left(\mathrm{CatH}_{2}\right)$, by $\mathrm{H}-$ atom transfer from the $\mathrm{CatH}^{\circ}$ radical to $\mathrm{ROO}^{\circ}$. Also in the case of hydroquinones $\left(\mathrm{QH}_{2}\right)$ the second $\mathrm{ROO}^{\circ}$ radical is trapped by $\mathrm{H}$-atom transfer from $\mathrm{QH}^{*}$, but the expected stoichiometry of 2 is diminished by the competition between the reactions of the semiquinone $\left(\mathrm{QH}^{*}\right)$ with $\mathrm{ROO}^{\circ}$ (to quench a second chain) or with $\mathrm{O}_{2}$, to afford $\mathrm{HOO}^{\circ}$, which propagates the autoxidation [21]. The effectiveness of an antioxidant is therefore described by two independent parameters: the inhibition rate constant $k_{\text {inh }}$ and the number of radical trapped $n$ (the stoichiometric factor). Analytical resolution of the kinetic equations, in the assumption that every ROO radical is trapped by $\mathrm{AH}$ and $\mathrm{A}^{*}$ (see (2)-(3)), affords (4) for the $\mathrm{O}_{2}$ consumption rate and (5) for the relationship between the length of the inhibition period $(\tau)$ and $R_{i}[10]$.

$$
\begin{aligned}
-\frac{d\left[\mathrm{O}_{2}\right]_{\mathrm{inh}}}{d t} & =\frac{k_{p}[\mathrm{RH}] R_{i}}{n k_{\mathrm{inh}}[\mathrm{AH}]}+R_{i} \\
R_{i} & =\frac{n[\mathrm{AH}]}{\tau}
\end{aligned}
$$

The typical oxygen consumption plots observed during inhibited autoxidation are reported in Figure 1(a). Trace (A) represents the $\mathrm{O}_{2}$ consumption during an uninhibited autoxidation, while traces (B-D) are those typically observed in the presence of antioxidants with low (B) intermediate (C) or high (D) $k_{\text {inh }}$ values.

Plots (C) and (D) of Figure 1(a) show a period in which the autoxidation of the substrate is strongly retarded by the antioxidant, the so-called "induction (or inhibition) period." The length of the inhibition period, graphically calculated as shown in Figure 1(a)(D), provides $\tau$, which in conjunction with $R_{i}$ and (5) affords the stoichiometric factor of the antioxidant. The slope of the inhibited period provides $-d\left[\mathrm{O}_{2}\right]_{\text {inh }} / d t$ that can be used to obtain $k_{\text {inh }}$ by (4).

A usual problem encountered when using (4) is that the rate of $\mathrm{O}_{2}$ consumption $-d\left[\mathrm{O}_{2}\right]_{\mathrm{inh}} / d t$ should be taken at the very beginning of the inhibited period, where the concentration of the antioxidant is actually equal to the initial concentration $[\mathrm{AH}]$, used in the equation. However, in practice this is often impossible due to the time required for system equilibration, so that the slope can be measured only after a certain time interval after the beginning of the reaction (see, for instance, the beginning of traces (C) and (D) in Figure 1(a)). While it is always possible to correct $[\mathrm{AH}]$ for the antioxidant concentration effectively present at the point in which the slope is measured, a better solution consists in using (6), that is, the integrated form of (4) [22].

$$
\begin{aligned}
\Delta\left[\mathrm{O}_{2}\right] & =\left[\mathrm{O}_{2}\right]_{t=0}-\left[\mathrm{O}_{2}\right]_{t} \\
& =-\left(\frac{k_{p}[\mathrm{RH}]}{k_{\mathrm{inh}}}\right)\left[\ln \left(1-\frac{t}{\tau}\right)\right]
\end{aligned}
$$

In this equation, the oxygen consumption after time $t$ is related to a logarithmic function of time, in the assumption that $n=2$. When plotting $\Delta\left[\mathrm{O}_{2}\right]$ as a function of $-\ln (1-$ $t / \tau)$, a straight line is obtained, whose slope is $k_{p}[\mathrm{RH}] / k_{\text {inh }}$, as shown in Figure 1(b).

When the antioxidant has a too low $k_{\text {inh }}$ to afford a recognizable induction period with a given substrate (see, for instance, Figure 1(a), trace (B)), (4) and (6) are no longer valid because a certain fraction of $\mathrm{ROO}^{\circ}$ radicals disappears by self-termination. Erroneous use of (4) and (6) in these cases may lead to large overestimation of $k_{\text {inh }}$. Changing the substrate with another one having lower $k_{p}$ and $2 k_{t}$ such as cumene usually overcomes this problem. However, when $k_{\text {inh }}$ is too low that also cumene is weakly inhibited, $k_{\text {inh }}$ can be obtained by (7), where $d\left[\mathrm{O}_{2}\right]_{0} / d t$ and $d\left[\mathrm{O}_{2}\right]_{\text {inh }} / d t$ are the $\mathrm{O}_{2}$ 


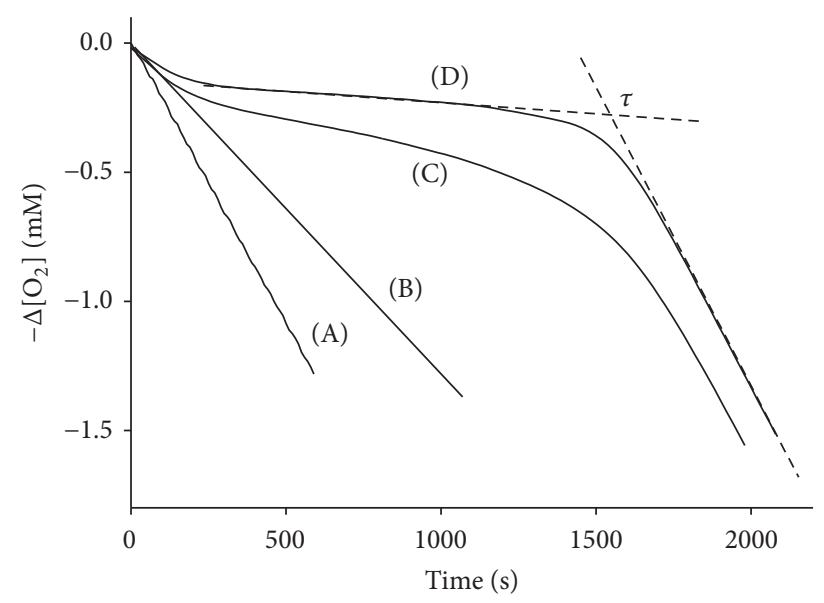

(a)

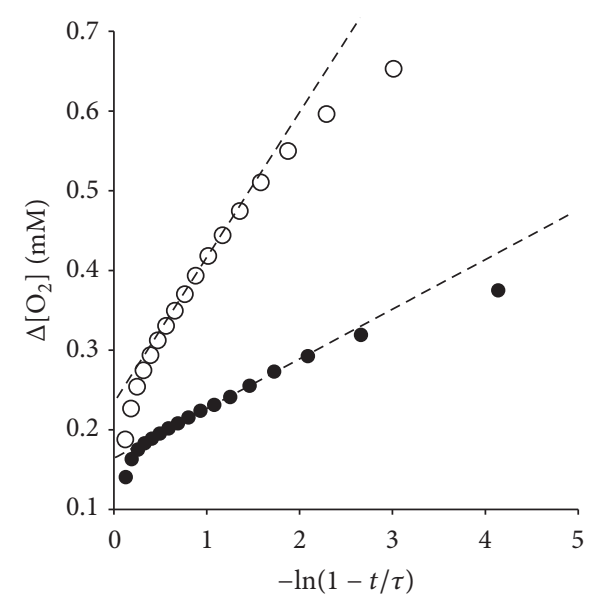

(b)

Figure 1: (a) Typical $\mathrm{O}_{2}$ consumption traces observed during the autoxidation of an organic substrate in the absence (A) or in the presence of antioxidants with low (B), intermediate (C), and high (D) $k_{\text {inh }}$ values. (b) Analysis of the $\mathrm{O}_{2}$ consumption by (6) for the antioxidants having intermediate $(\circ)$ and high $(\bullet) k_{\text {inh }}$.

consumption rates in the absence and in the presence of antioxidants, respectively.

$$
\frac{d\left[\mathrm{O}_{2}\right]_{0} / d t}{d\left[\mathrm{O}_{2}\right]_{\mathrm{inh}} / d t}-\frac{d\left[\mathrm{O}_{2}\right]_{\mathrm{inh}} / d t}{d\left[\mathrm{O}_{2}\right]_{0} / d t}=\frac{n k_{\mathrm{inh}}[\mathrm{AH}]}{\sqrt{2 k_{t} R_{i}}}
$$

On the other hand, very effective antioxidant may generate $\mathrm{O}_{2}$ consumption plots in which the slope of the inhibited period is nearly zero: in this case $k_{\text {inh }}$ values obtained either via (4) or (6) could be underestimated. In this regard, it is recommended to perform autoxidation experiments by using oxidizable substrates with different $k_{p}$ values, to properly analyze antioxidants with various potencies. Styrene, with $k_{p}$ of $41 \mathrm{M}^{-1} \mathrm{~s}^{-1}$, is used to measure $k_{\text {inh }}$ values in the range $10^{5}-10^{7} \mathrm{M}^{-1} \mathrm{~s}^{-1}$, while cumene $\left(k_{p}=0.32 \mathrm{M}^{-1} \mathrm{~s}^{-1}\right)$ is better suited for $k_{\text {inh }}$ values in the range $10^{3}-10^{5} \mathrm{M}^{-1} \mathrm{~s}^{-1}$. Kinetics faster than $10^{7} \mathrm{M}^{-1} \mathrm{~s}^{-1}$ can be determined by using methods based on the peroxyl radical clock, developed by Pratt et al. [23], while the development of oximetric methods for "fast" antioxidants is in progress in our laboratory. Autoxidation should be performed in solvents that are not reactive toward peroxyl radicals, such as chlorobenzene and acetonitrile. Solvents should not contain traces of acids or bases that could catalyze the reaction of $\mathrm{ROO}^{\circ}$ radicals [24-26].

\section{Differential Oxygen Uptake Apparatus}

Inhibited autoxidation kinetics can be determined by monitoring the disappearance of reactants, usually $\mathrm{O}_{2}$, or the formation of oxidation products (such as hydroperoxides or conjugated dienes) [27]; alternatively it can be monitored by tracking the cooxidation of an easily detectable probe [28]. Oxygen consumption experiments need to be performed in a closed system and the reaction can be monitored by one of several methods, such as by a polarographic probe [29], fluorescence quenching [30], or a pressure gauge [31].
The best-established method for bioorganic studies, in which accurate kinetic measurements are required, is based on the use of a differential pressure transducer [22]. The apparatus, shown in Figure 2, consists of two identical reaction vessels (reference and sample) connected through high performance liquid chromatography (HPLC) tubing to the opposite sides of the membrane of a variable reluctance differential pressure transducer [32].

The equilibration or the isolation of the two channels is made possible by a three-way valve, and all equipment is placed in a thermostatic bath. A mixture containing the oxidizable substrate (typically from $15 \%$ to $75 \% \mathrm{vol} / \mathrm{vol}$ ) and the initiator in a suitable high-boiling solvent (typically chlorobenzene or acetonitrile) are loaded in both reaction vessels. The reference flask also contains a large excess $(1 \mathrm{mM})$ of a very good antioxidant (often the $\alpha$-tocopherol analogue 2,2,5,7,8-pentamethyl-6-chromanol) to completely stop autoxidation (except the initiation step). Solutions are continuously stirred to ensure equilibration with air inside the system at the temperature of the experiment $\left(30-50^{\circ} \mathrm{C}\right)$ and, after a few minutes, the 3-way valve is closed and the $\mathrm{O}_{2}$ consumption during the uninhibited autoxidation is recorded. When a constant consumption is reached, the 3-way valve is opened and a concentrated solution of antioxidant is rapidly injected into the sample vessel by means of a microsyringe through the opening of a glass tap, then the 3-way valve is closed again. From this point on, the recording of the effect of the antioxidant on the autoxidation starts. A typical plot of an autoxidation measured in this way is reported in Figure 3, where the time-point of antioxidant injection is marked by an arrow.

The response of the sensor (in $\mathrm{mV} / \mathrm{V}$ ) is transformed in oxygen consumption $(\mathrm{M})$ by using a conversion factor, which is determined in separate calibration experiments. Calibration consists in performing autoxidation of an oxidizable substrate with known oxidizability (i.e., styrene) inhibited by the reference antioxidant 2,2,5,7,8-pentamethyl-6-chromanol (PMHC), whose stoichiometry of radical trapping is 2 . 


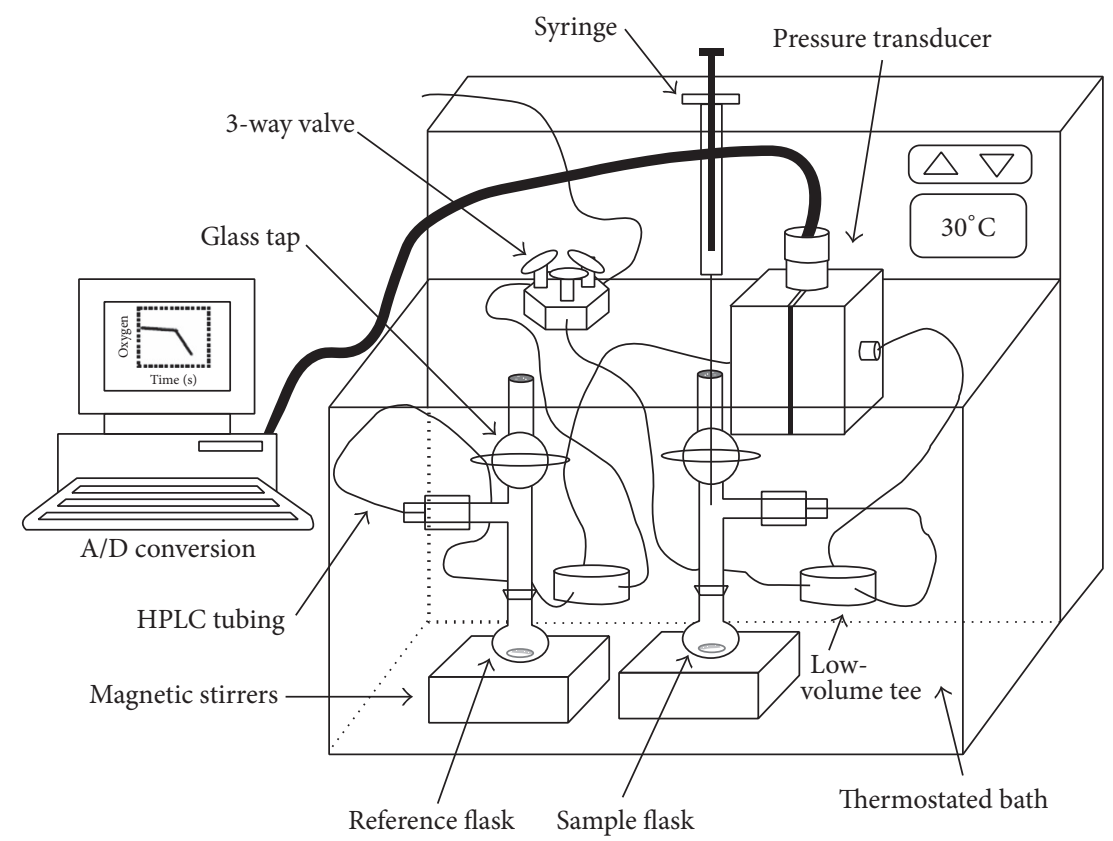

FIGURE 2: Differential oxygen uptake apparatus for autoxidation kinetics. Reprinted with permission from reference [32].

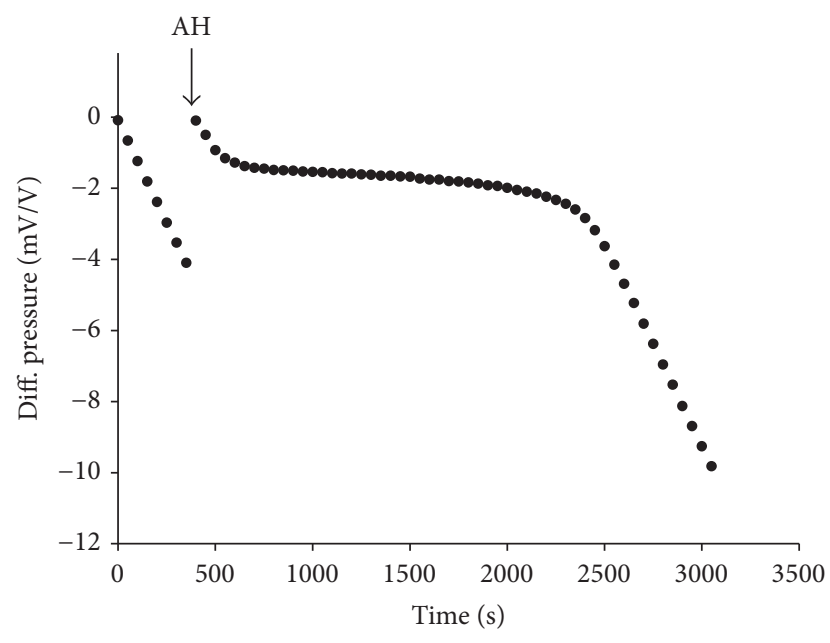

FIGURE 3: Differential pressure profile measured during the autoxidation of styrene inhibited by $\mathrm{PMHC}$ at $30^{\circ} \mathrm{C}$ in chlorobenzene. The arrow indicates the injection of the antioxidant. Reaction conditions were styrene $4.3 \mathrm{M}$; AIBN 0.05 M, PMHC: $5.0 \mu \mathrm{M}$.

The induction period length $(\tau)$ provides $R_{i}(5)$, while the expected $d\left[\mathrm{O}_{2}\right] / d t$ for the uninhibited autoxidation can be calculated from the known oxidizability of the substrate by using (1). The conversion factor $(a)$ is therefore defined as $d\left[\mathrm{O}_{2}\right] / d t=a \times d(\mathrm{mV} / \mathrm{V}) / d t$.

It should be noted that this instrumental set-up ensures that the pressure effects given by $\mathrm{N}_{2}$ evolution, which is due to azo-initiator decomposition, are compensated by the presence of the same amount of azo-initiator in the reference flask. For the same reason, also $\mathrm{O}_{2}$ consumption by initiating $\mathrm{I}^{\bullet}$ radicals is compensated and additive term $\left(+R_{i}\right)$ in (1) and (4) has to be skipped when analyzing $\mathrm{O}_{2}$ slopes. The instrument described above has been used in the last years in our laboratory to develop, among others, new classes of sulfur-containing heterocyclic antioxidants [33, 34], novel pyridine and pyrimidine radical-trapping derivatives [13], and to study the reactions with peroxyl radicals of natural polyphenols [20].

\section{Autoxidation Kinetics in Water Solution}

A considerable number of chain-breaking antioxidants is water-soluble, but little of their chemistry with peroxyl radicals is known in water, because of the limited availability of practical investigation methods. While oximetry may represent a promising way to address this lack of knowledge, as a matter of facts this method is limited by the poor water-solubility of typical oxidizable substrates. Previous efforts consisted in incorporating the substrate into micelles or liposomes [29, 31, 35]. Unfortunately, in heterogeneous systems the observed rate constants reflect the rate of reactants exchange between the particles. In these systems, the reactivity of different biomolecules with peroxyl radicals mostly depends on their lipophilicity [36]. We have recently reported that tetrahydrofuran (THF) presents most of the ideal features for an oxidizable substrate to be used in aqueous solutions, as it is miscible with buffered water; it is readily available in high purity (distillation can be used to remove the stabilizer) and it undergoes reasonably rapid autoxidation [37]. Autoxidation of THF proceeds by hydrogen abstraction from $\alpha$ position as exemplified in Scheme 3, and the reaction can be conveniently initiated by the water-soluble azoinitiator AAPH.

The oxidizability of THF is independent from $\mathrm{pH}$, and $k_{p}$ and $2 k_{t}$ in water were measured by us as 4.8 and 


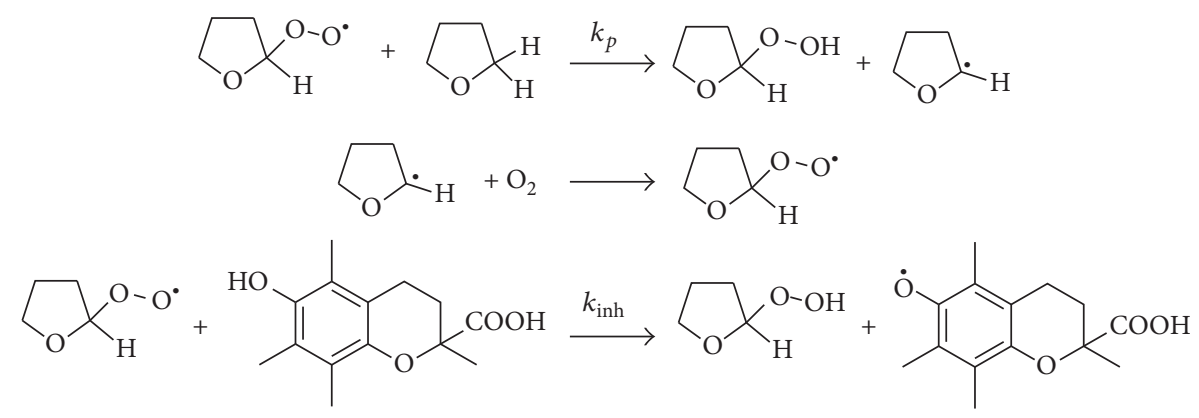

Scheme 3: Propagation steps of the autoxidation of tetrahydrofuran in water and inhibition by Trolox.

TABLE 2: Values of $k_{\text {inh }}\left(\mathrm{M}^{-1} \mathrm{~s}^{-1}\right)$ in buffered water and in organic solvents of different polarity.

\begin{tabular}{lcccc}
\hline Antioxidant & Water, pH 2.1 & Water, pH 7.4 & PhCl & MeCN \\
\hline Trolox & $(1.4 \pm 0.3) \times 10^{5^{\mathrm{a}}}$ & $(4.1 \pm 0.7) \times 10^{5^{\mathrm{a}}}$ & $1.1 \times 10^{6^{\mathrm{b}}}$ & $(1.6 \pm 0.2) \times 10^{5^{\mathrm{c}}}$ \\
PMHC & $(1.9 \pm 0.3) \times 10^{5^{\mathrm{a}}}$ & $(2.0 \pm 0.3) \times 10^{5^{\mathrm{a}}}$ & $3.2 \times 10^{6^{\mathrm{d}}}$ & $6.8 \times 10^{5^{\mathrm{e}}}$ \\
DBHA $^{\mathrm{f}}$ & $(3.3 \pm 0.4) \times 10^{4^{\mathrm{a}}}$ & $(3.2 \pm 0.4) \times 10^{4^{\mathrm{a}}}$ & $1.1 \times 10^{5^{\mathrm{a}}}$ & $2.5 \times 10^{4^{\mathrm{e}}}$ \\
Catechol & $(3 \pm 1) \times 10^{3^{\mathrm{a}}}$ & $(7 \pm 2) \times 10^{3^{\mathrm{a}}}$ & $5.5 \times 10^{5}$ & $2.5 \times 10^{4^{\mathrm{d}}}$ \\
\hline
\end{tabular}

${ }^{\mathrm{a}}$ See [37]; ${ }^{\mathrm{b}}$ see [38]; ${ }^{\mathrm{c}}$ see [39]; ${ }^{\mathrm{d}}$ see [13]; ${ }^{\mathrm{e}}$ see [24]; ${ }^{\mathrm{f}}$ 2,6-di-tert-butyl-4-methoxyphenol; ${ }^{\mathrm{g}}$ see [40].

$6.6 \times 10^{7} \mathrm{M}^{-1} \mathrm{~s}^{-1}$ at $30^{\circ} \mathrm{C}$ [37]. This method allowed us to measure for the first time $k_{\text {inh }}$ values for antioxidants of biological relevance at various $\mathrm{pH}$ as reported in Table 2, while the investigation of the deuterium kinetic isotope effect (DKIE) provided insight into the mechanism of protoncoupled electron transfer from phenols to peroxyl radicals.

\section{Kinetics Studies with Hydroperoxyl Radicals}

Hydroperoxyl radicals (HOO ${ }^{\bullet}$ ) are mediators of many important (bio)chemical processes, but their reactivity with phenolic antioxidants has often been neglected, mainly because this radical is hard to be monitored by common spectroscopic methods [41]. We have recently shown that autoxidation of 1,4-cyclohexadiene in conjunction with oximetry performed by a differential pressure transducer represents an easy way to study the reaction of this radical. It is known that, under air, 1,4-cyclohexadiene undergoes autoxidation to benzene, the propagating radical being $\mathrm{HOO}^{\circ}$ instead of an alkylperoxyl radical (see Scheme 4), and that antioxidants can slow down the process [15].

However, the measure of $k_{\text {inh }}$ was precluded by the complex kinetics that were observed, due to the unusual shape of the $\mathrm{O}_{2}$ consumption plots and to the strong solvent dependence of $k_{p}$ and $2 k_{t}$ (see Table 3 ).

We have recently demonstrated that the reason of the first anomaly is the two-faced behavior of the $\mathrm{HOO}^{\circ}$ radical that can both abstract a $\mathrm{H}$-atom from the antioxidant and reduce the corresponding phenoxyl radical back to the starting phenol, as indicated in Scheme 4. Thanks to Gepasi software (see Section 6), we could disentangle this complex kinetic behavior and obtain $k_{\text {inh }}$ values for the analogue of $\alpha$-tocopherol $\mathrm{PMHC}\left(k_{\mathrm{inh}}\right.$ in Scheme 4$)$ and the ratio between two possible reactions between $\mathrm{PMHC}$ radical and $\mathrm{HOO}^{\circ}\left(k_{\mathrm{Reg}} / k_{\mathrm{Ter}}\right.$ in
TABLE 3: Propagation $\left(k_{p} / \mathrm{M}^{-1} \mathrm{~s}^{-1}\right)$ and termination $\left(2 k_{t} \times 10^{-6} /\right.$ $\mathrm{M}^{-1} \mathrm{~s}^{-1}$ ) rate constants for the autoxidation of 1,4-cyclohexadiene in different solvents and corresponding rate constants for the reaction of PMHC with hydroperoxyl radicals $\left(k_{\mathrm{inh}} / \mathrm{M}^{-1} \mathrm{~s}^{-1}\right.$ and $\left.k_{\mathrm{Reg}} / k_{\mathrm{Ter}}\right)$ at $30^{\circ} \mathrm{C}$.

\begin{tabular}{lcccc}
\hline Solvent & $k_{p}$ & $2 k_{t}$ & $k_{\text {inh }}{ }^{\mathrm{b}}\left(\mathrm{HOO}^{\circ}\right)$ & $k_{\text {Reg }} / k_{\mathrm{Ter}}^{\mathrm{b}}$ \\
\hline $\mathrm{CCl}_{4}$ & $3800^{\mathrm{a}}$ & $5600^{\mathrm{a}}$ & $(1.6 \pm 0.4) \times 10^{7}$ & $9.9 \pm 3.5$ \\
$\mathrm{PhCl}$ & $1400^{\mathrm{a}}$ & $630^{\mathrm{a}}$ & $(1.6 \pm 0.1) \times 10^{6}$ & $8.3 \pm 0.5$ \\
$\mathrm{MeCN}$ & $350^{\mathrm{a}}$ & $4.3^{\mathrm{a}}$ & $(6.8 \pm 0.7) \times 10^{4}$ & $2.2 \pm 1.0$ \\
Dioxane & $385^{\mathrm{b}}$ & $6.3^{\mathrm{b}}$ & $(1.1 \pm 0.1) \times 10^{5}$ & $5.2 \pm 0.9$ \\
$\mathrm{THF}$ & $230^{\mathrm{b}}$ & $1.3^{\mathrm{b}}$ & $(2.5 \pm 0.5) \times 10^{4}$ & $0.5 \pm 0.1$ \\
$\mathrm{Me}_{2} \mathrm{SO}$ & $160^{\mathrm{c}}$ & $0.017^{\mathrm{c}}$ & & \\
\hline
\end{tabular}

${ }^{\mathrm{a}}$ See [15]; ${ }^{\mathrm{b}}$ see [42]; ${ }^{\mathrm{c}}$ see [43].

Scheme 4), which lead either to regeneration or to termination (see Table 3 ). These experiments showed for the first time that the $\mathrm{H}$-atom abstracting ability of $\mathrm{HOO}^{\bullet}$ is decreased by $\mathrm{H}$-bond formation $\left(\mathrm{S}-\mathrm{-HOO}^{\circ}\right)$ with polar solvents $(\mathrm{S})$, as the strength of this noncovalent interaction is weaker in the transition state than in the reactants. H-bond formation is also the reason why $k_{p}$ and $2 k_{t}$ of 1,4 -cyclohexadiene are smaller in polar solvents than in nonpolar ones [42].

\section{Complex Kinetics Analysis by Using Gepasi Software}

Extraction of kinetic information from oximetry studies during inhibited autoxidation is straightforward when the antioxidant and the oxidizable substrate are both "well behaved" and obey (2)-(3) described above. When this is no longer true, a more sophisticated analysis based on numerical fitting of kinetic data should be used, by means of dedicated 


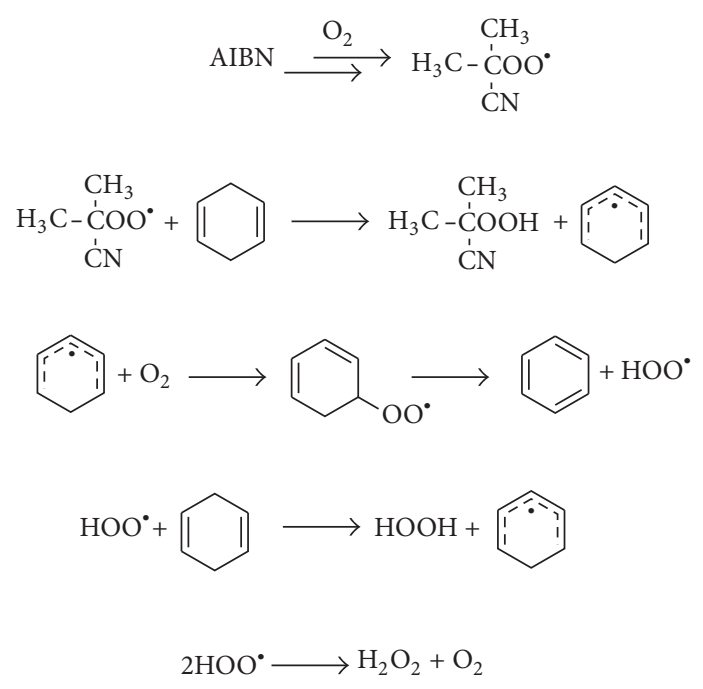<smiles>Cc1c(C)c2c(c(C)c1O)CCC(C)(C)O2</smiles>

(PMHC)

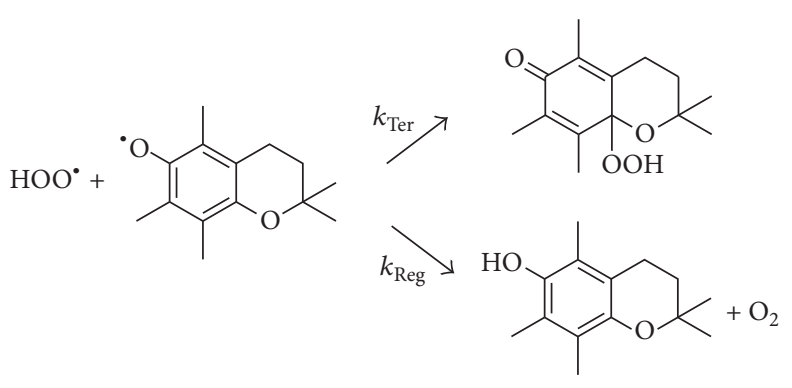

Scheme 4: Autoxidation of 1,4-cyclohexadiene inhibited by the analogue of $\alpha$-tocopherol PMHC.

software such as Gepasi, which is freely available on the web at the developer site http://www.gepasi.org/. This software simulates the kinetics of (bio)chemical reactions and, with the help of numerical algorithms, enables us to fit models to data and optimize any function of the model. Model building is straightforward as it only requires the list of the reactions that take place in the system [44]. In this section, we report an example of the application of Gepasi to the interpretation of the complex autoxidation experiments collected during the study the antioxidant activity of an allicin (1) analogue isolated from Petiveria alliacea, (S)-benzyl phenylmethanethiosulfinate (2) (Scheme 5).

As shown in Figure 4, the rate of oxygen consumption and the length of the inhibition period were not related to the antioxidant concentration, as predicted instead by (4) and (5) [45].

However, in a series of studies aimed at clarifying the antioxidant activity of garlic-derived thiosulfinates similar to allicin (1), it was discovered that the active molecule able to trap peroxyl radical was not (1) itself, but the sulfenic acid that derives from its decomposition by Cope elimination
(Scheme 5) [46, 47]. Therefore, we hypothesized that the odd kinetic traces depended on a preliminary equilibrium to yield the "true" antioxidant species. By using the reported data for the decomposition of (2), the autoxidation curves were analyzed by the Gepasi software which provided the unknown $k_{\text {inh }}$ constant for the sulfenic acid (3) as $(2.8 \pm 1.2) \times$ $10^{7} \mathrm{M}^{-1} \mathrm{~s}^{-1}$ (at $30^{\circ} \mathrm{C}$ ) that is about 10 times larger than that of $\alpha$-tocopherol [38, 45]. Interestingly, Gepasi software allowed us to calculate the concentrations of (2) and (3) during the course of the reaction, as reported in Figure 4(b). At the end of the inhibition period (which lasted about 8000 seconds), more than $50 \%$ of (2) was still present in solution, while the concentration of the "active" sulfenic acid (3) dropped to zero. This showed that, differently to "well-behaved" antioxidants, the inhibition period did not end when all antioxidant was depleted, but when the production rate of the active specie (sulfenic acid) by the thiosulfinate is insufficient to keep the pace and compete effectively with propagation.

\section{Analysis of Nanoantioxidants}

Nanoantioxidants are a class of emerging materials that are based on nanoparticles having intrinsic radical scavenging activity or that are functionalized with antioxidants. The efficacy of nanoantioxidants can easily be assessed by oximetry using a differential pressure transducer as this method is not influenced by the color of the solution or by the presence of suspended particles [48]. As an example, we will describe the study of CoNPsTOH, magnetic nanoparticles, based on a graphite-coated cobalt core having the diameter of $50 \mathrm{~nm}$ (CoNPs) [49], that were functionalized by click chemistry with a phenolic antioxidant derived from Trolox (TOH) [50]. Their antioxidant activity was investigated and compared to that of nanoparticles lacking the pendant antioxidant and to $\mathrm{TOH}$ alone, as depicted in Figure 5(a). Results showed that such nanoantioxidants were very active in inhibiting the autoxidation of styrene, with $k_{\text {inh }}$ values higher than $\mathrm{TOH}$. However, the length of the induction period was shorter than expected, presumably because the proximity of the phenolic moieties favors the self-recombination of two phenoxyl radicals instead of the quenching of a second peroxyl radical. The photographs in Figure 5(b) show that the magnetic nanoantioxidants stick on the stir bar, while, after the stirring is turned on, they are well dispersed in solution.

Two additional examples of nanoantioxidants were recently studied by oximetry methods. They both consisted in halloysite nanotubes (NHT) [51] that had been grafted or grafted and loaded with phenols. In the first study, the natural antioxidant curcumin was grafted on the surface of halloysite nanotubes by thiol-disulfide chemistry (HNTcur), with the aim of obtaining a prodrug with a controlled curcumin release on dependence of both intracellular glutathione $(\mathrm{GSH})$ and $\mathrm{pH}$ conditions. HNT-cur showed good antioxidant activity toward cumene autoxidation, with $k_{\text {inh }}$ comparable to that of curcumin alone $\left(1.7 \times 10^{4} \mathrm{M}^{-1} \mathrm{~s}^{-1}\right.$ in $\mathrm{PhCl}$ ). Similar to CoNPsTOH, the stoichiometric coefficient was shorter than that of curcumin [52]. The second example is represented by a synergic nanoantioxidant, obtained by different functionalization of the external surface and the inner 
<smiles>C=CCSS(=O)CC=C</smiles>

Allicin (1)

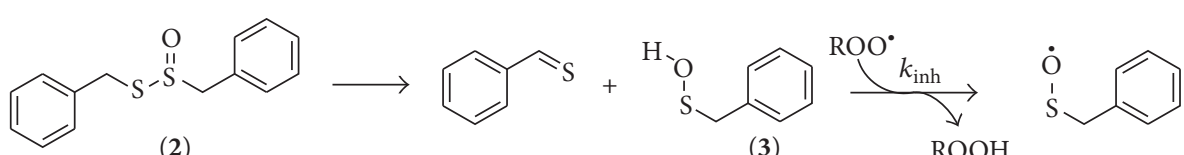

(2)

(3)

$\mathrm{ROOH}$

SCHEme 5: Formation of the active radical-trapping sulfenic acid (3) from decomposition of benzyl phenylmethanethiosulfinate (2), an analogue of allicin (1).

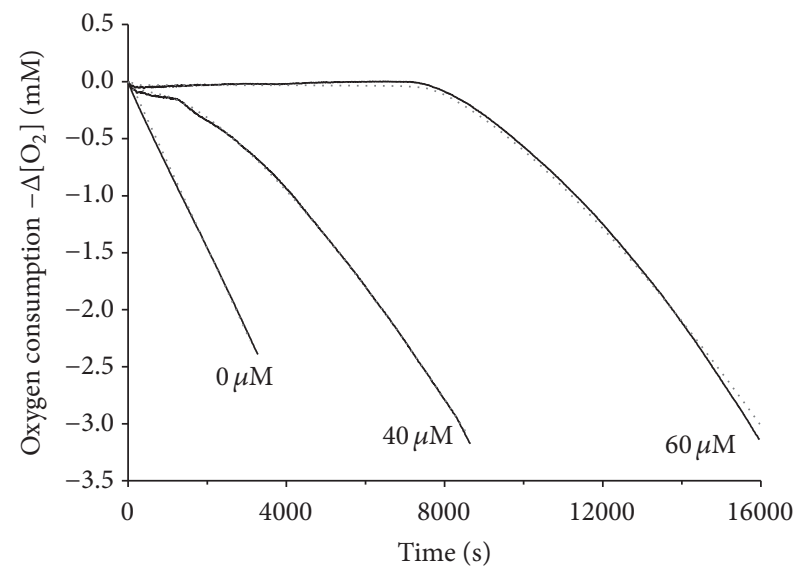

(a)

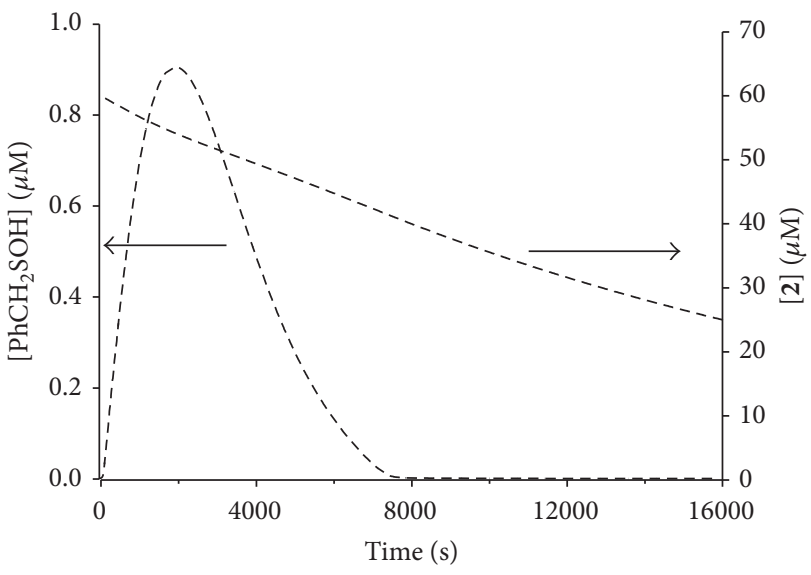

(b)

FIgURE 4: Analysis of autoxidation traces by the Gepasi software. (a) Experimental (solid lines) and simulated (dotted lines) $\mathrm{O}_{2}$ consumption during the autoxidation of cumene in the presence of variable amounts of thiosulfinate (2). (b) Variations of the concentration of thiosulfinate (2) and sulfenic acid (3), obtained by simulation based on kinetic data determined in (a) at the concentration of $60 \mu \mathrm{m}$. Reprinted with permission from [45].

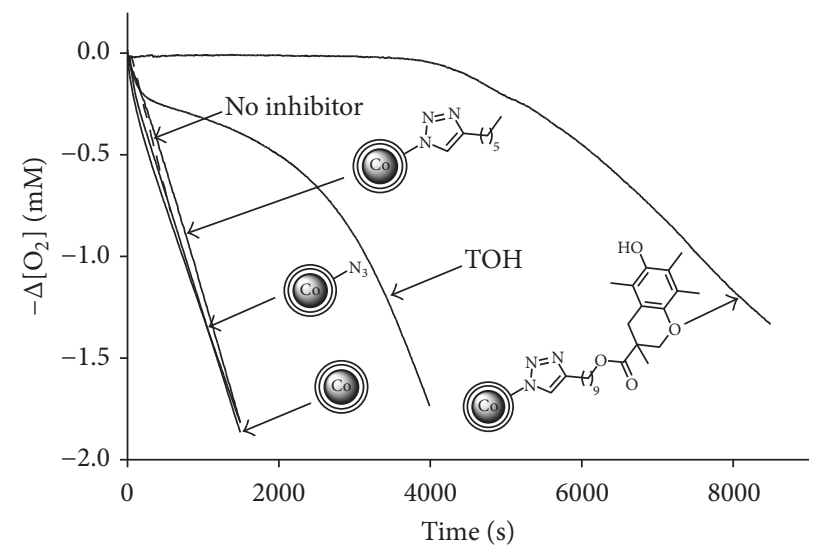

(a)

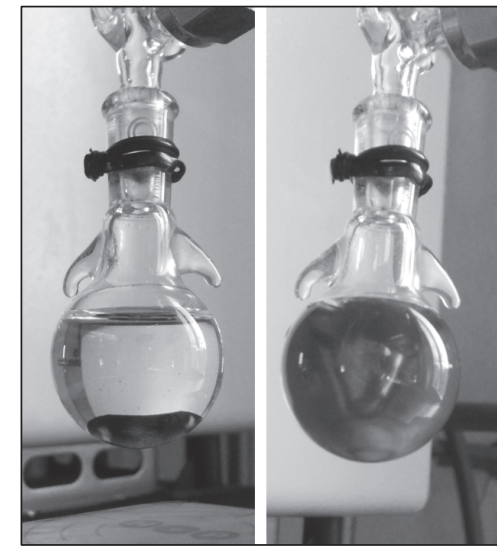

(b)

FIGURE 5: (a) Oxygen consumption during the autoxidation of styrene (4.3 M) in PhCN initiated by AIBN ( $25 \mathrm{~mm})$ at $30^{\circ} \mathrm{C}$ without inhibitor, $3.8 \mu \mathrm{M}$ of TOH or with $0.15 \mathrm{mg} \mathrm{mL}^{-1}$ of various CoNPs without the phenolic moiety, and CoNPsTOH (corresponding to a concentration of $\mathrm{TOH}$ groups of $14.4 \mu \mathrm{M}$ ); $R_{i}=3.6 \times 10^{-9} \mathrm{Ms}^{-1}$. (b) Photographs of the reaction vessels of the pressure transducer apparatus containing the CoNPs in the absence (left) and in the presence (right) of magnetic stirring. Reprinted with permission from [50]. 


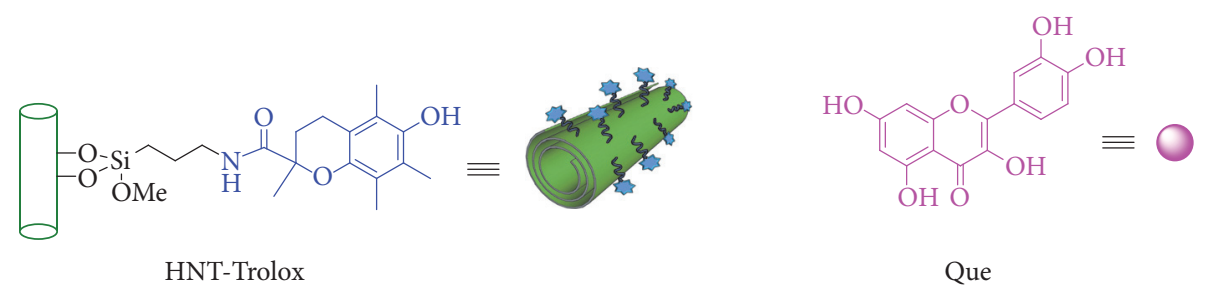

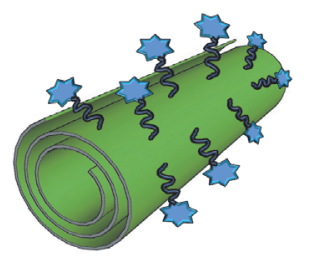

HNT-Trolox

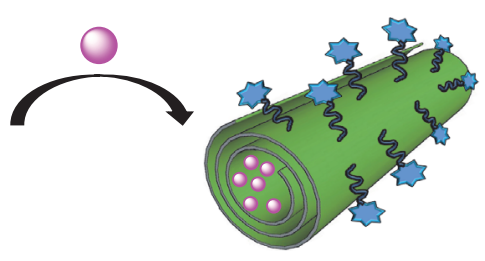

HNT-Trolox/que

FIGURE 6: Schematic representation of quercetin loading into HNT-Trolox. Reproduced from [39] with permission from the Royal Society of Chemistry.

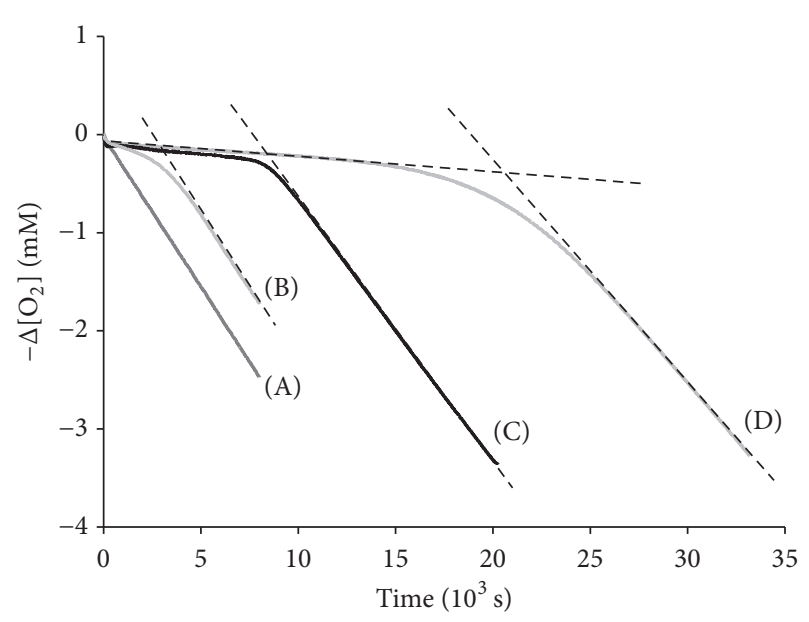

(a)

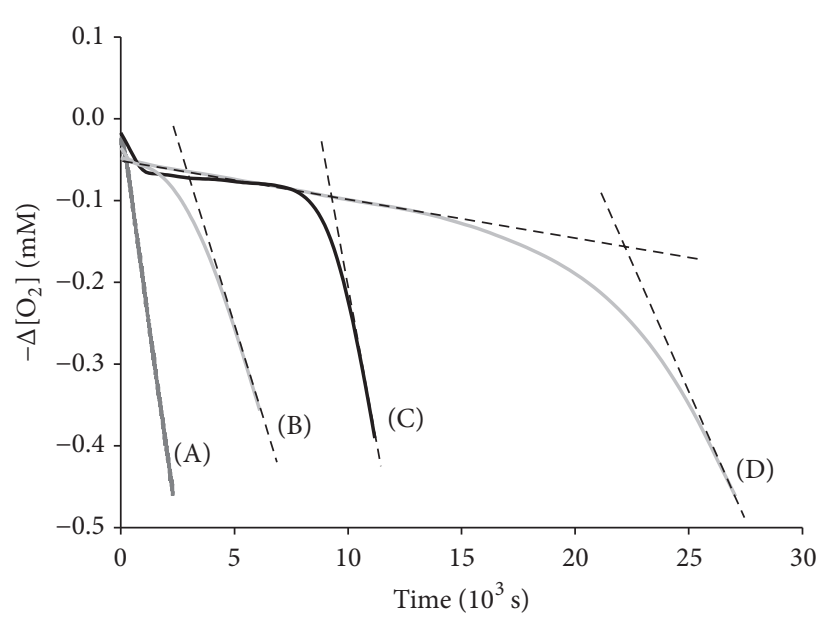

(b)

FIGURE 7: Inhibition of the autoxidation of cumene in acetonitrile (a) or chlorobenzene (b) by $0.1 \mathrm{mg} \mathrm{mL}^{-1}$ of: pristine HNT (A), HNT/Que (B), HNT-Trolox (C), and HNT-Trolox/Que (D). Reproduced from [39] with permission from the Royal Society of Chemistry.

lumen of halloysite nanotubes. Trolox, a mimic of natural $\alpha$-tocopherol, was selectively grafted on the HNT external surface, while quercetin, a natural polyphenolic antioxidant, was loaded into the inner lumen to afford HNT-Trolox/Que, a bifunctional nanoantioxidant (see Figure 6) [39].

Autoxidation studies in cumene, reported in Figure 7, showed that NHT functionalized by Trolox (HNT-Trolox) had a good antioxidant activity (lines (C)), while quercetin loaded into HNT (HNT/Que) had a poor performance (traces (B)), due to its slow kinetic of release.

Interestingly, the presence of both grafted Trolox and loaded quercetin in HNT-Trolox/Que improved the overall antioxidant performance more than expected from an additive contribution of the two antioxidants, as it can be inferred by comparing traces (B), (C), and (D) in Figure 7. Accurate kinetic analysis by the oximetry method allowed us to conclude that the synergy between Trolox and quercetin was due to the regeneration of Trolox from its radical by quercetin, occurring at the nanotube external surface [39].

\section{Challenges and Perspectives}

The main limitations of the technique described herein are low productivity (one sample at time), long reaction times $(>2 \mathrm{~h}$ for a run), and relatively large volumes of reagents $(0.5-4 \mathrm{~mL})$. In our experience, in research routine these drawbacks are largely overcome by many advantages, which are among others the strength of the instrumentation, the low running costs, and the wide range of chemical compatibility (from fully organic to aqueous solvents) which make differential uptake devices more versatile than $\mathrm{O}_{2}$ optical sensors.

Future improvements should be directed toward the miniaturization of the reaction vessels and toward the possibility of running several samples at one time. Such improvements 
have been achieved in case of $\mathrm{O}_{2}$-optical sensing by using microfluidic devices [53]. Besides, the quest of novel biologically relevant oxidizable substrates is an active research field that should be more deeply investigated. In this context, the possibilities of easily performing experiments in water environment (see Section 4) and working with $\mathrm{HOO}^{\circ}$ radicals (see Section 5) are just two examples of the capabilities of the differential uptake apparatus.

\section{Conclusion}

The differential oxygen uptake apparatus described herein represents a powerful and cost-effective way to obtain antioxidant activity from inhibited autoxidation studies. Among the many assays available in the literature, the measurement of $\mathrm{O}_{2}$ consumption during the inhibited autoxidation of a standard substrate is one of the most reliable and predictive methods, especially for structure-activity relationship studies [54-61]. These experiments provide the rate constants of the reaction between antioxidants with peroxyl radicals ( $\mathrm{ROO}^{\circ}$ ), which are involved in the propagation of radical damage [62]. The versatility of this method allows one to measure the activity of a wide variety of antioxidants (natural polyphenols, nanoantioxidants, bioactive sulfides, etc.) in organic and mixed water-organic solvents. We hope that this review will inspire researchers working in the field of antioxidants to adopt this powerful technique for their studies.

\section{Conflicts of Interest}

The authors declare that there are no conflicts of interest regarding the publication of this paper.

\section{Acknowledgments}

This work was supported by a grant to Luca Valgimigli, Andrea Baschieri, and Riccardo Amorati from the Italian MIUR (PRIN 2010-2011 2010PFLRJR, PROxi Project). Luca Valgimigli and Riccardo Amorati acknowledge funding from the University of Bologna (FARB Project FFBO123154).

\section{References}

[1] K. U. Ingold, "Peroxy radicals," Accounts of Chemical Research, vol. 2, no. 1, pp. 1-9, 1969.

[2] U. Neuenschwander and K. F. Jensen, "Olefin autoxidation in flow," Industrial and Engineering Chemistry Research, vol. 53, no. 2, pp. 601-608, 2014.

[3] H. Yin, L. Xu, and N. A. Porter, "Free radical lipid peroxidation: mechanisms and analysis," Chemical Reviews, vol. 111, no. 10, pp. 5944-5972, 2011.

[4] K. U. Ingold and D. A. Pratt, "Advances in radical-trapping antioxidant chemistry in the 21st century: a kinetics and mechanisms perspective," Chemical Reviews, vol. 114, no. 18, pp. $9022-$ 9046, 2014.

[5] J. M. C. Gutteridge and B. Halliwell, "Antioxidants: molecules, medicines, and myths," Biochemical and Biophysical Research Communications, vol. 393, no. 4, pp. 561-564, 2010.

[6] V. Roginsky and E. A. Lissi, "Review of methods to determine chain-breaking antioxidant activity in food," Food Chemistry, vol. 92, no. 2, pp. 235-254, 2005.
[7] M. Takashima, M. Horie, M. Shichiri, Y. Hagihara, Y. Yoshida, and E. Niki, "Assessment of antioxidant capacity for scavenging free radicals in vitro: a rational basis and practical application," Free Radical Biology and Medicine, vol. 52, no. 7, pp. 1242-1252, 2012.

[8] R. Amorati and L. Valgimigli, "Advantages and limitations of common testing methods for antioxidants," Free Radical Research, vol. 49, no. 5, pp. 633-649, 2015.

[9] T. A. Dix and J. Aikens, "Mechanisms and biological relevance of lipid peroxidation initiation," Chemical Research in Toxicology, vol. 6, no. 1, pp. 2-18, 1993.

[10] M. Lucarini and G. F. Pedulli, "Free radical intermediates in the inhibition of the autoxidation reaction," Chemical Society Reviews, vol. 39, no. 6, pp. 2106-2119, 2010.

[11] D. A. Pratt and N. A. Porter, "Role of hyperconjugation in determining carbon-oxygen bond dissociation enthalpies in alkylperoxyl radicals," Organic Letters, vol. 5, no. 4, pp. 387-390, 2003.

[12] J. A. Howard and K. U. Ingold, "Absolute rate constants for hydrocarbon autoxidation. VI. Alkyl aromatic and olefinic hydrocarbons," Canadian Journal of Chemistry, vol. 45, no. 8, pp. 793-802, 1967.

[13] L. Valgimigli, D. Bartolomei, R. Amorati et al., "3-Pyridinols and 5-pyrimidinols: tailor-made for use in synergistic radicaltrapping co-antioxidant systems," Beilstein Journal of Organic Chemistry, vol. 9, no. 1, pp. 2781-2792, 2013.

[14] J. A. Howard and K. U. Ingold, "Absolute rate constants for hydrocarbon autoxidation. XVII. The oxidation of some cyclic ethers," Canadian Journal of Chemistry, vol. 47, no. 20, pp. 3809$3815,1969$.

[15] J. A. Howard and K. U. Ingold, "Absolute rate constants for hydrocarbon autoxidation. V. The hydroperoxy radical in chain propagation and termination," Canadian Journal of Chemistry, vol. 45, no. 8, pp. 785-792, 1967.

[16] G. E. Zaikov, J. A. Howard, and K. U. Ingold, "Absolute rate constants for hydrocarbon autoxidation. XIII. Aldehydes: photooxidation, co-oxidation, and inhibition," Canadian Journal of Chemistry, vol. 47, no. 16, pp. 3017-3029, 1969.

[17] L. Melone, S. Prosperini, G. Ercole, N. Pastori, and C. Punta, "Is it possible to implement N-hydroxyphthalimide homogeneous catalysis for industrial applications? A case study of cumene aerobic oxidation," Journal of Chemical Technology and Biotechnology, vol. 89, no. 9, pp. 1370-1378, 2014.

[18] F. Recupero and C. Punta, "Free radical functionalization of organic compounds catalyzed by N-hydroxyphthalimide," Chemical Reviews, vol. 107, no. 9, pp. 3800-3842, 2007.

[19] R. Amorati and G. F. Pedulli, "Do garlic-derived allyl sulfides scavenge peroxyl radicals?" Organic \& Biomolecular Chemistry, vol. 6, no. 6, pp. 1103-1107, 2008.

[20] R. Amorati, J. Zotova, A. Baschieri, and L. Valgimigli, "Antioxidant activity of magnolol and honokiol: kinetic and mechanistic investigations of their reaction with peroxyl radicals," The Journal of Organic Chemistry, vol. 80, no. 21, pp. 10651-10659, 2015.

[21] V. Roginsky, T. Barsukova, D. Loshadkin, and E. Pliss, "Substituted p-hydroquinones as inhibitors of lipid peroxidation," Chemistry and Physics of Lipids, vol. 125, no. 1, pp. 49-58, 2003.

[22] G. W. Burton and K. U. Ingold, "Autoxidation of biological molecules. 1. The antioxidant activity of vitamin $\mathrm{E}$ and related chain-breaking phenolic antioxidants in vitro," Journal of the American Chemical Society, vol. 103, no. 21, pp. 6472-6477, 1981. 
[23] D. A. Pratt, K. A. Tallman, and N. A. Porter, "Free radical oxidation of polyunsaturated lipids: new mechanistic insights and the development of peroxyl radical clocks," Accounts of Chemical Research, vol. 44, no. 6, pp. 458-467, 2011.

[24] L. Valgimigli, R. Amorati, S. Petrucci et al., "Unexpected acid catalysis in reactions of peroxyl radicals with phenols," Angewandte Chemie-International Edition, vol. 48, no. 44, pp. 8348-8351, 2009.

[25] R. Amorati, L. Valgimigli, G. F. Pedulli, S. A. Grabovskiy, N. N. Kabal'nova, and C. Chatgilialoglu, "Base-promoted reaction of 5-hydroxyuracil derivatives with peroxyl radicals," Organic Letters, vol. 12, no. 18, pp. 4130-4133, 2010.

[26] E. A. Haidasz, D. Meng, R. Amorati et al., "Acid is key to the radical-trapping antioxidant activity of nitroxides," Journal of the American Chemical Society, vol. 138, no. 16, pp. 5290-5298, 2016.

[27] J. J. Hanthorn, E. Haidasz, P. Gebhardt, and D. A. Pratt, "A versatile fluorescence approach to kinetic studies of hydrocarbon autoxidations and their inhibition by radical-trapping antioxidants," Chemical Communications, vol. 48, no. 81, pp. 1014110143, 2012.

[28] E. A. Haidasz, A. T. M. Van Kessel, and D. A. Pratt, "A continuous visible light spectrophotometric approach to accurately determine the reactivity of radical-trapping antioxidants," Journal of Organic Chemistry, vol. 81, no. 3, pp. 737-744, 2016.

[29] K. Jodko-Piórecka and G. Litwinienko, "Antioxidant activity of dopamine and L-DOPA in lipid micelles and their cooperation with an analogue of $\alpha$-tocopherol," Free Radical Biology and Medicine, vol. 83, pp. 1-11, 2015.

[30] X. H. Kai, V. Y. Waisundara, M. Timmins et al., "High-throughput quantitation of peroxyl radical scavenging capacity in bulk oils," Journal of Agricultural and Food Chemistry, vol. 54, no. 15, pp. 5299-5305, 2006.

[31] E. A. Mengele, I. G. Plashchina, and O. T. Kasaikina, "Kinetics of lecithin oxidation in liposomal aqueous solutions," Colloid Journal, vol. 73, no. 6, pp. 815-821, 2011.

[32] L. Valgimigli and D. A. Pratt, "Antioxidants in chemistry and biology," in Encyclopedia of Radicals in Chemistry, Biology and Materials, C. Chatgilialoglu and A. Studer, Eds., vol. 3, pp. 16231677, John Wiley \& Sons, Chichester, UK, 2012.

[33] S. Menichetti, R. Amorati, V. Meoni, L. Tofani, G. Caminati, and C. Viglianisi, "Role of noncovalent sulfur * oxygen interactions in phenoxyl radical stabilization: synthesis of super tocopherollike antioxidants," Organic Letters, vol. 18, no. 21, pp. 5464-5467, 2016.

[34] C. Viglianisi, R. Amorati, L. Di Pietro, and S. Menichetti, "A straightforward route to potent phenolic chain-breaking antioxidants by acid-promoted transposition of 1, 4-benzo[b]oxathiines to dihydrobenzo[b]thiophenes," Chemistry, vol. 21, no. 46, pp. 16639-16645, 2015.

[35] M. Musialik, M. Kita, and G. Litwinienko, "Initiation of lipid autoxidation by ABAP at $\mathrm{pH} 4-10$ in SDS micelles," Organic \& Biomolecular Chemistry, vol. 6, no. 4, pp. 677-681, 2008.

[36] L. Castle and M. J. Perkins, "Inhibition kinetics of chain-breaking phenolic antioxidants in SDS micelles. Evidence that intermicellar diffusion rates may be rate-limiting for hydrophobic inhibitors such as .alpha.-tocopherol," Journal of the American Chemical Society, vol. 108, no. 20, pp. 6381-6382, 1986.

[37] R. Amorati, A. Baschieri, G. Morroni, R. Gambino, and L. Valgimigli, "Peroxyl radical reactions in water solution: a gym for proton-coupled electron-transfer theories," Chemistry-A European Journal, vol. 22, no. 23, pp. 7924-7934, 2016.
[38] G. W. Burton, T. Doba, E. J. Gabe et al., "Autoxidation of biological molecules. 4. Maximizing the antioxidant activity of phenols," Journal of the American Chemical Society, vol. 107, no. 24, pp. 7053-7065, 1985.

[39] M. Massaro, S. Riela, S. Guernelli et al., "A synergic nanoantioxidant based on covalently modified halloysite-trolox nanotubes with intra-lumen loaded quercetin," Journal of Materials Chemistry B, vol. 4, no. 13, pp. 2229-2241, 2016.

[40] A. Tarozzi, M. Bartolini, L. Piazzi et al., "From the dual function lead AP2238 to AP2469, a multi-target-directed ligand for the treatment of Alzheimer's disease," Pharmacology Research \& Perspectives, vol. 2, no. 2, Article ID e00023, 2014.

[41] Z. Kozmér, E. Arany, T. Alapi, E. Takács, L. Wojnárovits, and A. Dombi, "Determination of the rate constant of hydroperoxyl radical reaction with phenol," Radiation Physics and Chemistry, vol. 102, pp. 135-138, 2014.

[42] J. Cedrowski, G. Litwinienko, A. Baschieri, and R. Amorati, "Hydroperoxyl radicals (HOO•): vitamin E regeneration and H-bond effects on the hydrogen atom transfer," Chemistry $-A$ European Journal, vol. 22, no. 46, pp. 16441-16445, 2016.

[43] D. T. Sawyer, M. S. McDowell, and K. S. Yamaguchi, "Reactivity of perhydroxyl (HOO.bul.) with 1,4-cyclohexadiene (model for allylic groups in biomembranes)," Chemical Research in Toxicology, vol. 1, no. 2, pp. 97-100, 1988.

[44] P. Mendes, "Biochemistry by numbers: simulation of biochemical pathways with Gepasi 3," Trends in Biochemical Sciences, vol. 22, no. 9, pp. 361-363, 1997.

[45] R. Amorati, P. T. Lynett, L. Valgimigli, and D. A. Pratt, “The reaction of sulfenic acids with peroxyl radicals: insights into the radical-trapping antioxidant activity of plant-derived thiosulfinates," Chemistry - A European Journal, vol. 18, no. 20, pp. 6370-6379, 2012.

[46] V. Vaidya, K. U. Ingold, and D. A. Pratt, "Garlic: source of the ultimate antioxidants-sulfenic acids," Angewandte ChemieInternational Edition, vol. 48, no. 1, pp. 157-160, 2009.

[47] P. T. Lynett, K. Butts, V. Vaidya, G. E. Garrett, and D. A. Pratt, "The mechanism of radical-trapping antioxidant activity of plant-derived thiosulfinates," Organic and Biomolecular Chemistry, vol. 9, no. 9, pp. 3320-3330, 2011.

[48] N. L. Pacioni, V. Filippenko, N. Presseau, and J. C. Scaiano, "Oxidation of copper nanoparticles in water: mechanistic insights revealed by oxygen uptake and spectroscopic methods," Dalton Transactions, vol. 42, no. 16, pp. 5832-5838, 2013.

[49] R. N. Grass, E. K. Athanassiou, and W. J. Stark, "Covalently functionalized cobalt nanoparticles as a platform for magnetic separations in organic synthesis," Angewandte Chemie-International Edition, vol. 46, no. 26, pp. 4909-4912, 2007.

[50] C. Viglianisi, V. Di Pilla, S. Menichetti et al., "Linking an $\alpha$ tocopherol derivative to cobalt (0) nanomagnets: magnetically responsive antioxidants with superior radical trapping activity and reduced cytotoxicity," Chemistry - A European Journal, vol. 20, no. 23, pp. 6857-6860, 2014.

[51] M. Du, B. Guo, and D. Jia, "Newly emerging applications of halloysite nanotubes: a review," Polymer International, vol. 59, no. 5, pp. 574-582, 2010.

[52] M. Massaro, R. Amorati, G. Cavallaro et al., "Direct chemical grafted curcumin on halloysite nanotubes as dual-responsive prodrug for pharmacological applications," Colloids and Surfaces B: Biointerfaces, vol. 140, pp. 505-513, 2016.

[53] B. Kuswandi, Nuriman, J. Huskens, and W. Verboom, "Optical sensing systems for microfluidic devices: a review," Analytica Chimica Acta, vol. 601, no. 2, pp. 141-155, 2007. 
[54] L. R. C. Barclay, M. R. Vinqvist, K. Mukai, S. Itoh, and H. Morimoto, "Chain-breaking phenolic antioxidants: steric and electronic effects in polyalkylchromanols, tocopherol analogs, hydroquinones, and superior antioxidants of the polyalkylbenzochromanol and naphthofuran class," Journal of Organic Chemistry, vol. 58, no. 26, pp. 7416-7420, 1993.

[55] S. C. Mojumdar, D. A. Becker, G. A. DiLabio, J. J. Ley, L. R. C. Barclay, and K. U. Ingold, "Kinetic Studies on Stilbazulenyl-bisnitrone (STAZN), a nonphenolic chain-breaking antioxidant in solution, micelles, and lipid membranes," Journal of Organic Chemistry, vol. 69, no. 9, pp. 2929-2936, 2004.

[56] L. R. C. Barclay and M. R. Vinqvist, "Membrane peroxidation: inhibiting effects of water soluble antioxidants on phospholipids of different charge types," Free Radical Biology \& Medicine, vol. 16, no. 6, pp. 779-788, 1994.

[57] L. R. C. Barclay, C. E. Edwards, and M. R. Vinqvist, "Media effects on antioxidant activities of phenols and catechols," Journal of the American Chemical Society, vol. 121, no. 26, pp. 62266231, 1999.

[58] F. Antunes, L. R. C. Barclay, K. U. Ingold et al., "On the antioxidant activity of melatonin," Free Radical Biology and Medicine, vol. 26, no. 1-2, pp. 117-128, 1999.

[59] G. L. Hatfield and L. R. C. Barclay, "Bilirubin as an antioxidant: kinetic studies of the reaction of bilirubin with peroxyl radicals in solution, micelles, and lipid bilayers," Organic Letters, vol. 6, no. 10, pp. 1539-1542, 2004.

[60] M. Frenette, P. D. MacLean, L. R. C. Barclay, and J. C. Scaiano, "Radically different antioxidants: thermally generated carboncentered radicals as chain-breaking antioxidants," Journal of the American Chemical Society, vol. 128, no. 51, pp. 16432-16433, 2006.

[61] C. Viglianisi, M. G. Bartolozzi, G. F. Pedulli, R. Amorati, and S. Menichetti, "Optimization of the antioxidant activity of hydroxy-substituted 4-thiaflavanes: a proof-of-concept study," Chemistry-A European Journal, vol. 17, no. 44, pp. 1239612404, 2011.

[62] P. Mulder, H.-G. Korth, and K. U. Ingold, "Why quantumthermochemical calculations must be used with caution to indicate 'a promising lead antioxidant,' Helvetica Chimica Acta, vol. 88, no. 2, pp. 370-374, 2005. 

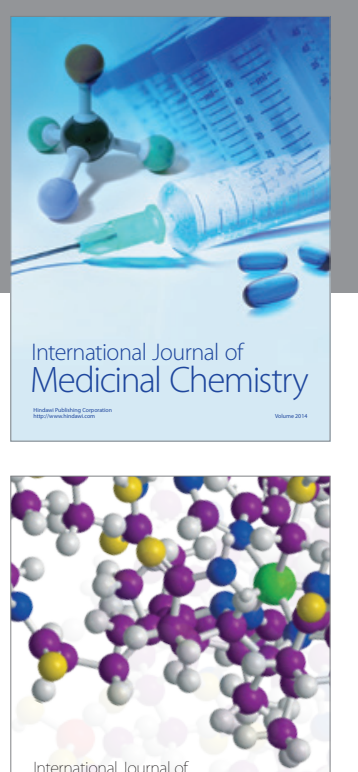

Carbohydrate Chemistry

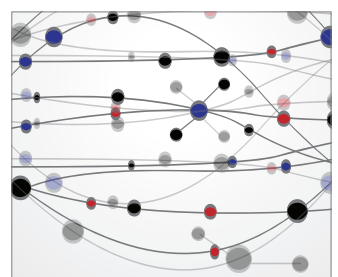

The Scientific World Journal
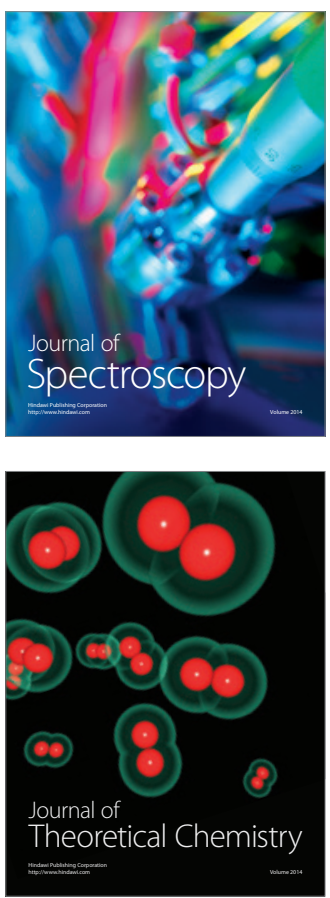
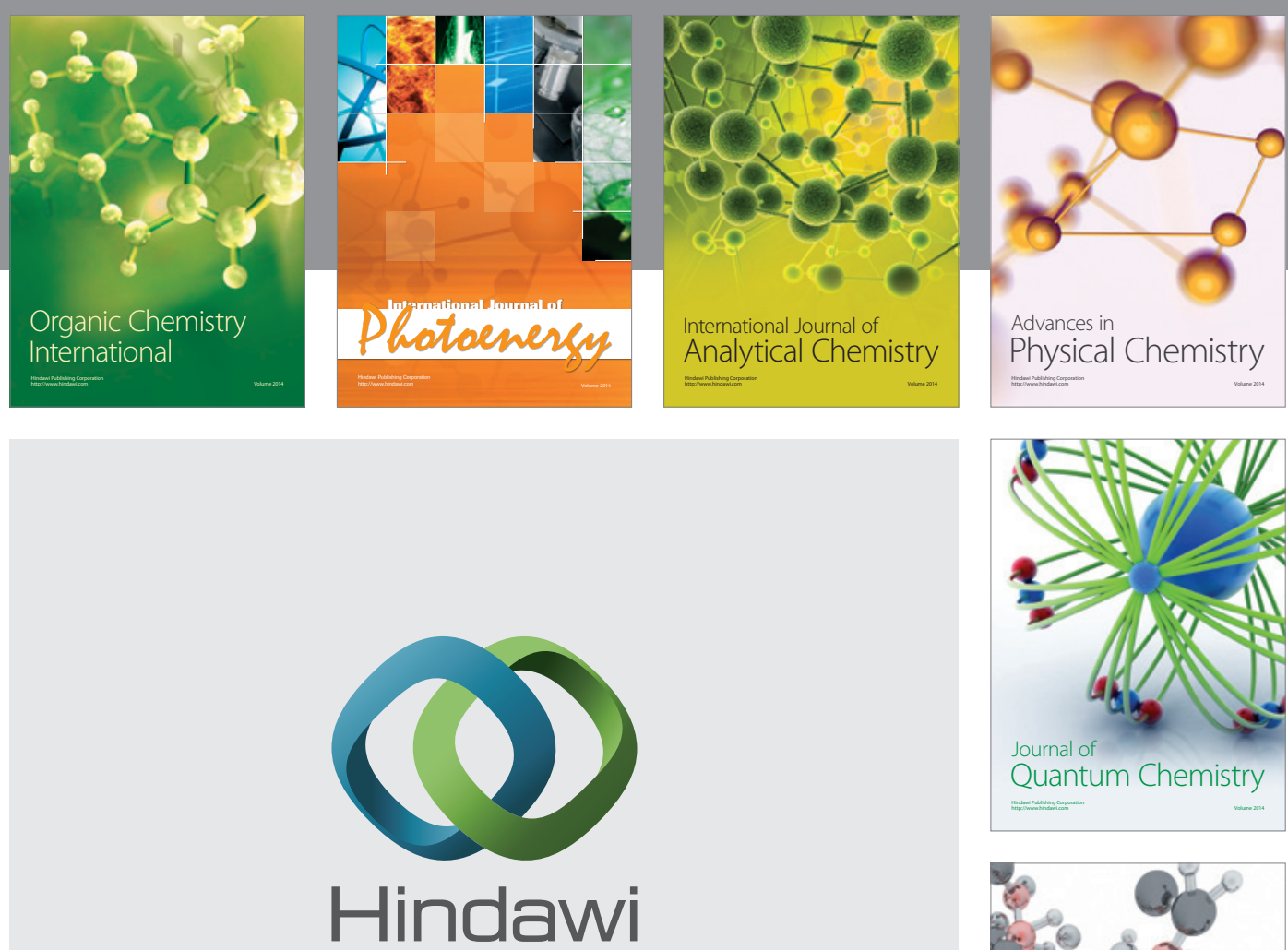

Submit your manuscripts at

https://www.hindawi.com

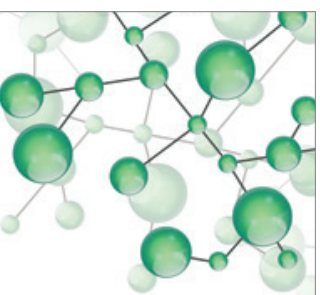

International Journal of

Inorganic Chemistry
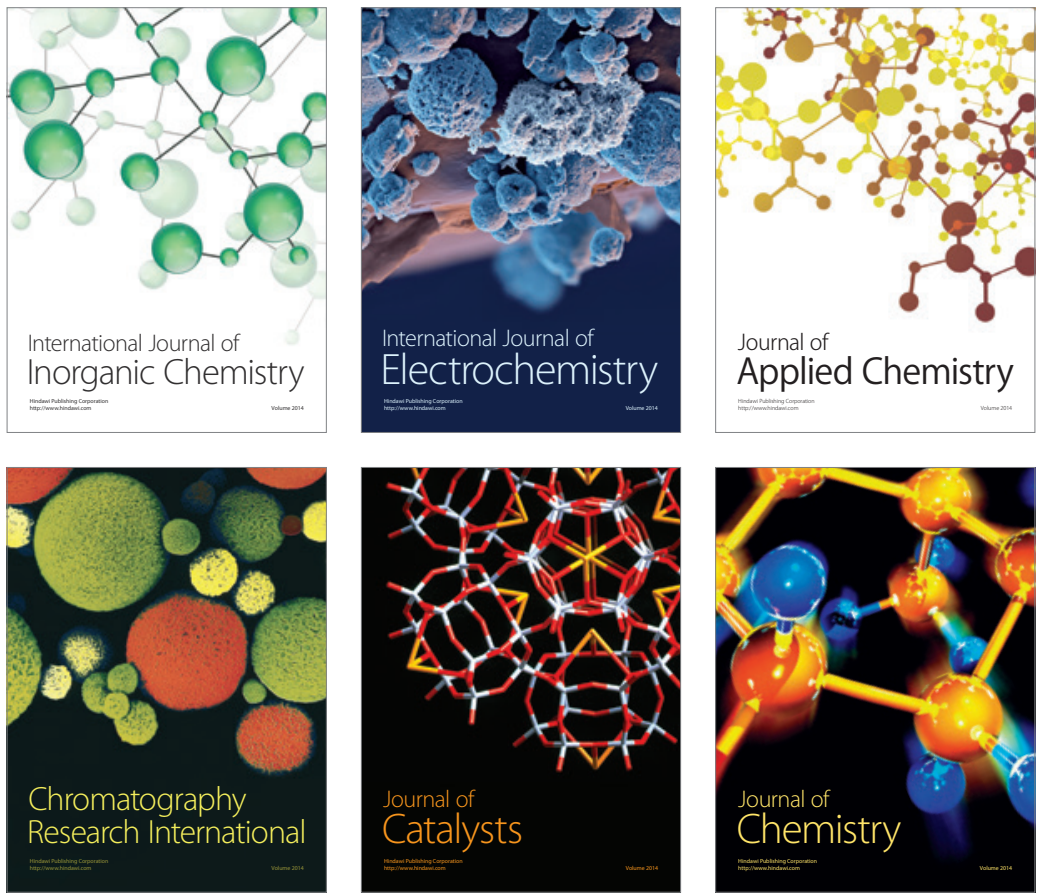

Journal of

Applied Chemistry
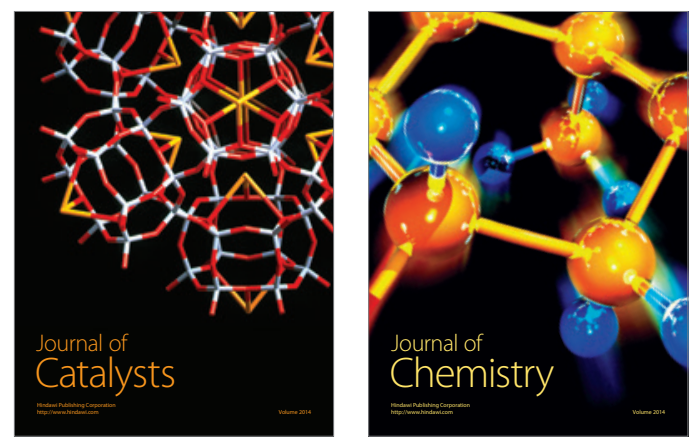
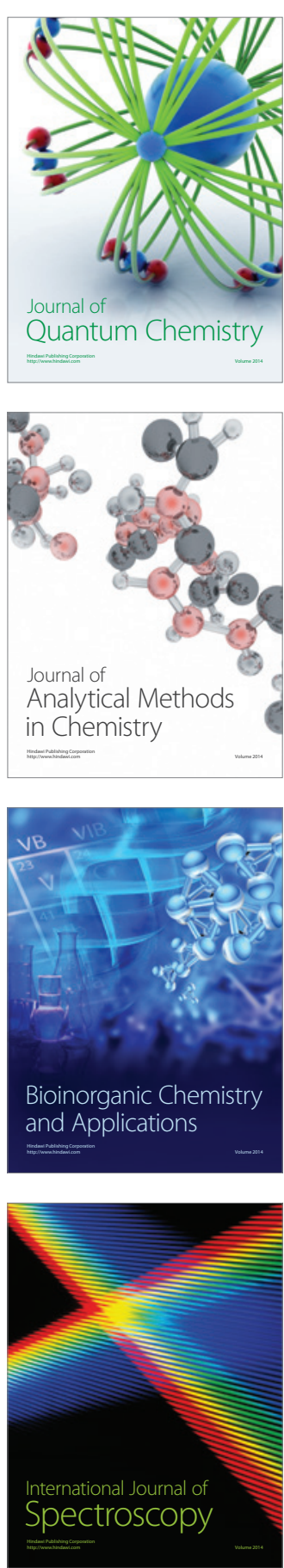